\title{
Comparative analysis of MAPK and MKK gene families reveals differential evolutionary patterns in Brachypodium distachyon inbred lines
}

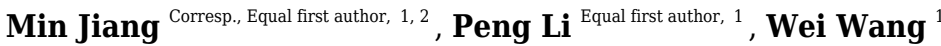 \\ ${ }^{1}$ Shanghai Key Laboratory of Plant Functional Genomics and Resources, Shanghai Chenshan Plant Science Research Center, Shanghai Institutes for \\ Biological Sciences, Chinese Academy of Sciences (CAS), Shanghai Chenshan Botanical Garden, Shanghai, China \\ 2 Ministry of Education Key Laboratory for Biodiversity Science and Ecological Engineering, Insititute of Biodiversity Science, School of Life Sciences, \\ Fudan University, Shanghai, China \\ Corresponding Author: Min Jiang \\ Email address: yijinsha@126.com
}

Background : Mitogen-activated protein kinase (MAPK) cascades are involved with signal transduction in almost every aspect of plant growth and development, as well as biotic and abiotic stress responses. The evolutionary analysis of MAPKs and MKKs in individual or entire plant species has been reported, but the evolutionary patterns in the diverse inbred lines of Brachypodium distachyon are still unclear. Results: We conducted the systematical molecular evolutionary analysis of $B$. distachyon. A total of 799 MAPKs and 618 MKKs were identified from 53 B. distachyon inbred lines. Remarkably, only three inbred lines had 16 MPKs and most of those inbred lines lacked MPK7-2 members, whereas 12 MKKs existed in almost all $B$. distachyon inbred lines. Phylogenetic analysis indicated that MAPKs and MKKs were divided into four groups as previously reported, grouping them in the same branch as corresponding members. MPK21-2 was the exception and fell into two groups, which may be due to their exon-intron patterns, especially the untranslation regions (UTRs). We also found that differential evolution patterns of MKK10 paralogues from ancient tandem duplicates may have undergone functional divergence. Expression analyses suggested that MAPKS and MKKs likely played different roles in different genetic contexts within various tissues and with abiotic stresses. Conclusion: Our study revealed that UTRs affected the structure and evolution of MPK21-2 genes and the differential evolution of MKK10 paralogues with ancient tandem duplication might have functional divergences. Our findings provided new insights into the functional evolution of genes in closely inbred lines. 


\section{Comparative analysis of $M A P K$ and $M K K$ gene families reveals}

\section{2 differential evolutionary patterns in Brachypodium distachyon}

\section{3 inbred lines}

4 Min Jiang ${ }^{1,2, \#, *}$, Peng Li ${ }^{1 \#}$, and Wei Wang ${ }^{1}$

$5{ }^{1}$ Shanghai Key Laboratory of Plant Functional Genomics and Resources, Shanghai Chenshan

6 Plant Science Research Center, Shanghai Institutes for Biological Sciences, Chinese Academy of

7 Sciences (CAS), Shanghai Chenshan Botanical Garden, Shanghai, China

8 2Ministry of Education Key Laboratory for Biodiversity Science and Ecological Engineering,

9 Insititute of Biodiversity Science, School of Life Sciences, Fudan University, Shanghai, China

10 \# These authors contributed equally in this work.

11 * Correspondence: Min Jiang (yijinsha@126.com)

\section{Authors' email addresses:}

Min Jiang: yijinsha@,126.com

Peng Li: $\underline{381778082 @ q q . c o m}$

Wei Wang:1514034946@qq.com

\section{Abstract}

Background: Mitogen-activated protein kinase (MAPK) cascades are involved with signal transduction in almost every aspect of plant growth and development, as well as biotic and abiotic stress responses. The evolutionary analysis of MAPKs and MKKs in individual or entire plant species has been reported, but the evolutionary patterns in the diverse inbred lines of Brachypodium distachyon are still unclear.

Results: We conducted the systematical molecular evolutionary analysis of $B$. distachyon. A total of 799 MAPKs and 618 MKKs were identified from 53 B. distachyon inbred lines. Remarkably, only three inbred lines had 16 MPKs and most of those inbred lines lacked MPK7-2 members, whereas 12 MKKs existed in almost all B. distachyon inbred lines. Phylogenetic analysis indicated that MAPKs and MKKs were divided into four groups as previously reported, grouping them in the same branch as corresponding members. MPK21-2 was the exception and fell into two groups, which may be due to their exon-intron patterns, especially the untranslation regions (UTRs). We also found that differential evolution patterns of MKK10 paralogues from ancient tandem duplicates may have undergone functional divergence. Expression analyses suggested that $M A P K s$ and $M K K s$ likely played different roles in different genetic contexts within various tissues and with abiotic stresses.

Conclusion: Our study revealed that UTRs affected the structure and evolution of MPK21-2 genes and the differential evolution of $M K K 10$ paralogues with ancient tandem duplication might 
have functional divergences. Our findings provided new insights into the functional evolution of genes in closely inbred lines.

\section{Introduction}

Mitogen-activated protein kinase (MAPK or MPK) signaling cascades play vital roles in the stress response, cell division, and developmental regulation. They are divided into three highlyconserved subfamilies that continuously act in a sequential manner in evolution and fundamental signaling transduction pathways (Rodriguez et al., 2010; Xu and Zhang, 2015; Jagodzik et al., 2018). The MAPK kinase kinases (MKKKs or MEKKs) are activated by extracellular cues and subsequently phosphorylate and activate the $\mathrm{S} / \mathrm{T}-\mathrm{X}_{3-5}-\mathrm{S} / \mathrm{T}$ motif of downstream MAPK kinases (MAPKKs or MKKs), which, in turn, phosphorylate and activate MAPKs at their TXY activation loop (Rodriguez et al., 2010, Singh et al., 2012). Activated MPKs regulate downstream cellular targets, including regulatory and metabolic enzymes and transcription regulators (Joo et al., 2008, Guan et al., 2014).

Brachypodium distachyon $(2 \mathrm{n}=10)$ is an annual temperate grass with a close phylogenetic relationship to other temperate cereals and an intermediate position within the Pooideae subfamily (Soreng et al., 2015; Catalan et al., 2016). B. distachyon is desirable for its small physical stature, rapid life cycle, ability to self-fertilize, and small diploid genome size (Draper et al., 2001; Garvin et al., 2008). Highly efficient Agrobacterium-mediated transformation methods in Brachypodium have also been established (Vain et al., 2008; Vogel and Hill, 2008). Therefore, $B$. distachyon is widely used as a model plant for studying problems unique to cereals and grasses (Vogel et al., 2010; Brkljacic et al., 2011; Mur et al., 2011; Catalan et al., 2014). The morphological, molecular, and cytological analyses of diverse $B$. distachyon inbred lines have been conducted (Filiz et al., 2009; Vogel et al., 2009) and their nuclear and plastid genomes have been deep sequenced and annotated (Gordon et al., 2014; Gordon et al., 2017; Sancho et al. 2018). Further analysis showed that the inbred lines of $B$. distachyon are divided into three different genomic groups, including a mostly Extremely Delayed Flowering (EDF+) clade, a mostly Spanish $(\mathrm{S}+)$ clade, and a Turkish $(\mathrm{T}+)$ clade, based on their flowering phenotype and geographical substructure (Sancho et al., 2018).

To date, the evolutionary mechanisms of MAPK cascades in plants have indicated a diverse domain organization and novel activation loop variants (Mohanta et al., 2015) and/or distinct expansion mechanism (Jiang and Chu, 2018). A variety of single-gene duplication types emerged continuously and have involved in the plant's adaptation to dramatically changing environments (Wang et al., 2009; Cuevas et al., 2016). However, whole-genome duplications (WGDs) are considered to be a major force in the evolution of morphological and physiological diversity (Soltis et al., 2009; Paterson et al.; 2010). The ancient tandem duplication event occurred at the adjacent genes in the same chromosome, which are usually expanded or retained by an unequal crossing (Freeling, 2009). Tandem duplication often displays less expression difference and functional divergence than distant duplication (Makino and McLysaght, 2012; Ghanbarian and Hurst, 2015). However, there is limited information on the gene expansion mechanism and 
functional evolution of the MAPK cascades in diverse $B$. distachyon inbred lines, including for Bd21 (Chen et al., 2012; Jiang et al., 2015). We studied the evolutionary patterns of MAPKs and MKKs from different $B$. distachyon inbred lines. The phylogenetic relationships and the identification of MAPKs and MKKs were determined for $53 \mathrm{~B}$. distachyon inbred lines. We investigated gene and domain construction patterns of the individual members with a certain divergence and focused on the evolutionary history of $M K K 10$ paralogues in different $B$. distachyon inbred lines. This revealed various conservative and divergent tandem gene clusters. The expression patterns of these genes were analyzed in Bd21, BdTR8i, and Bd30-1 from three genetic groups in various tissues and abiotic stresses, and their potential functions were also investigated.

\section{Methods and materials}

\section{Identification of MAPK and MKK gene family members}

We downloaded gene information for $M A P K$ and $M K K$ from B. distachyon $\mathrm{Bd} 21$ from the PLAZA platform (https://bioinformatics.psb.ugent.be/plaza/) (Van Bel et al., 2018). BLASTP (Altschul et al. 1997) searches were conducted with a threshold of $90 \%$ identity; searches were performed with orthologous protein sequences using BdMAPKs and BdMKKs as queries in BrachyPan (https://brachypan.jgi.doe.gov/) (Gordon et al., 2017) to identify these genes in the 53 diverse $B$. distachyon inbred lines. Collected sequences were only accepted for scanning using InterPro software (Mitchell et al. 2019) if they harbored MAPK or MKK consensus sequences, including the activation loop TXY motif for MPKs, the active site motif $\mathrm{D}(\mathrm{L} / \mathrm{L} / \mathrm{V}) \mathrm{K}$, and the phosphorylation target site $\mathrm{S} / \mathrm{T}-\mathrm{X}_{5}-\mathrm{S} / \mathrm{T}$ within the activation loop for MKKs. The gene identifier information of these sequences was collected and is listed in Table S1 and Table S2.

\section{Gene structure and sequence alignments}

The exon/intron structure of identified MAPKs and MKKs was performed using Gene Structure Display Server (GSDS) software (http://gsds.cbi.pku.edu.cn/). All of the full-length amino acid sequences were initially aligned using Clustal Omega with default parameters (http://www.ebi.ac.uk/Tools/msa/clustalo/). The domains and motifs of MAPKs and MKKs were scanned using InterProScan software (http://www.ebi.ac.uk/interpro/) (Jones et al., 2014). The structural schematic of all members of MAPK and MKK were executed according to InterProScan analysis results. The alignment logos of the protein conserved domain were generated using the WebLogo3 application (http://weblogo.threeplusone.com/).

\section{Synteny and phylogenetic analyses}

The phylogenetic relationships of all $53 \mathrm{~B}$. distachyon inbred lines were generated in the BrachyPan project and visualized with the CorelDRAW X3 program. Phylogenetic trees were created based on the alignment of all MAPKs or MKKs using the maximum likelihood (ML) method with the Jones-Taylor-Thornton (JTT) model, 2,000 bootstrap values, and partial deletion by the MEGA 6.0 software, respectively (Tamura et al., 2013). The Neighbor Joining (NJ) Trees of the MAPKs or MKKs were also reconstructed with the same parameters using 
112 MEGA 6.0. We obtained the synteny information of duplicate genes and the tandem (TD) data 113 from the PlantDGD database (http://pdgd.njau.edu.cn:8080/) (Qiao et al., 2019).

114

115

116

117

118

119

120

121

122

123

124

125

126

127

128

129

130

131

132

133

134

135

136

137

138

139

140

141

142

143

144

145

146

147

148

149

\section{Plant sample preparation}

We sowed BdTR8i, Bd21, and Bd30-1 seeds in 1/2 MS medium in the dark for $4 \mathrm{~d}$ at $25^{\circ} \mathrm{C}$ and then transferred them to a soil mix. Plants were grown in a greenhouse under $14 \mathrm{~h}$ light $(21$ $\left.{ }^{\circ} \mathrm{C}\right) / 10 \mathrm{~h}$ dark $\left(18^{\circ} \mathrm{C}\right)$ photoperiods. We harvested the root, stem, leaf blade, and leaf sheath at the eight-to-nine leaf stage. Spikelet samples from $B$. distachyon were collected at the early flowering stages according to their different flowering times (Figure S1). For the abiotic stress treatment, 2-week-old $B$. distachyon seedlings were dipped in $1 / 2 \mathrm{MS}$ liquid medium containing $20 \%$ PEG 6000 and $200 \mathrm{mM} \mathrm{NaCl}$, and then plants were collected after treatment for $3 \mathrm{~h}$ and $6 \mathrm{~h}$, respectively. Moreover, seedlings were transferred to a growth chamber and heat-treated at $40{ }^{\circ} \mathrm{C}$ for $3 \mathrm{~h}$ and $6 \mathrm{~h}$. All samples were flash frozen in liquid nitrogen and stored at $-80{ }^{\circ} \mathrm{C}$ for RNA extraction.

\section{Expression analysis}

Total RNA was extracted from samples using Trizol reagent and 1-2 $\mu \mathrm{g}$ was reverse-transcribed into cDNA using PrimeScript RT Master Mix Perfect Real Time (TaKaRa) according to the manufacturer's instructions. The quality of total RNA was detected using Nanodrop1000 and its integrity was estimated by electrophoresis in $1.5 \%(\mathrm{w} / \mathrm{v})$ agarose gel. The real-time quantitative polymerase chain reaction (RT-qPCR) was carried out in $10 \mu \mathrm{l}$ reactions with 5-50 ng of firststand cDNA products $(4 \mu \mathrm{l}), 5$ pmol of each primer $(0.4 \mu \mathrm{l}), 5 \mu \mathrm{l}$ SYBR green master mix $(2 \mathrm{X})$, $0.2 \mu \mathrm{l}$ ROX as a passive reference standard to normalize the SYBR fluorescent signal. The conditions for RT-qPCR were: initial activation at $95{ }^{\circ} \mathrm{C}$ for $5 \mathrm{~min}$ followed by 45 cycles of 95 ${ }^{\circ} \mathrm{C}$ for $30 \mathrm{~s}$, and $60{ }^{\circ} \mathrm{C}$ for $30 \mathrm{~s}$. Subsequently, the specificity of PCR products was monitored using a melting curve analysis $\left(61-95{ }^{\circ} \mathrm{C}\right.$ with fluorescence read every $\left.0.5{ }^{\circ} \mathrm{C}\right)$. The $B$. distachyon actin (gene locus: Bradi2g24070) gene was used as an internal control for all RTqPCR analyses; specific primers for $M A P K$ and $M K K$ were listed in Table S3. Three independent biological replicates were conducted for each experiment. The relative expression of $M A P K$ and $M K K$ genes was calculated using the $2^{-\Delta \Delta \mathrm{Ct}}$ method.

\section{Results}

\section{Identification and annotation of MPKs and MKKs in 53 diverse $B$. distachyon inbred lines}

We identified the two gene families by searching homologous $\mathrm{Bd} 21$ sequences in the public BrachyPan database (Chen et al., 2012) to determine the conservation and divergence of MPKs and MKKs in 53 diverse $B$. distachyon inbred lines. All predicted MPKs and MKKs were named based on the similarity of their orthologous protein to that of $A$. thaliana and $B$. distachyon (Ichimura et al., 2002; Chen et al., 2012). Ultimately, a total of 799 MPKs and 618 MKKs were retrieved (Table 1, Table S4, and Table S5). We found that most B. distachyon inbred lines had 14 or 15 MPKs apart from Bd21, BdTR3c, and Bd18-1, which had 16 members (Table 1). Further analysis showed that only seven inbred lines had the MPK7-2 gene, including $\mathrm{Bd} 21$, 
150 Bd2-3, BdTR3c, Bd18-1, S8iiC, Mur1, and Foz1 (Table S1). This may be the result of an

151

152

153

154

155

156

157

158

159

160

161

162

163

164

165

166

167

168

169

170

171

172

173

174

175

176

177

178

179

180

181

182

183

184

185

186

187

188

incomplete annotation of the genome sequence or the long sequence of the MPK7-2 protein, which usually consists of 1,708 amino acid (aa) residues. Most B. distachyon inbred lines harbored 12 MKK members except Tek-4 (11), Bd3-1 (7), Adi-10 (10), Gaz-8 (5), ABR5 (11), Foz1 (11), and Jer1 (11) (Table 1 and Table S5). The incomplete assembly of Tek-4 (77.82\%), Bd3-1 (89.52\%), Adi-10 (89.52\%), and Gaz-8 (88.31\%) may be the reason that relatively few MKK members have been identified (Gordon et al., 2017). Further analysis showed that the $B$. distachyon inbred lines lacked a particular MKK member; for example, MKK10-5 of Tek-4, MKK10-4 of ABR5, MKK4 of Foz1, MKK5 of Jer1, MKK10-3 and -4 of Adi-10 (Table S2). We also incorporated the available genomic detailed information from MPKs and MKKs (Table S1 and Table S2).

\section{Phylogenetic classification of $B$. distachyon inbred lines MAPKs and MKKs}

To investigate the phylogenetic relationship of MPK proteins in diverse B. distachyon inbred lines, the phylogeny of all identified 799 MPK protein sequences were performed using ML and NJ methods, respectively. As expected, all homologues for each of the 16 Bd21 MPKs (BdMPKs) were divided into four groups (A, B, C, and D) and clustered on the corresponding branch except Tek-4MPK16 (Figures 1, S2 and S3). Tek-4MPK16 consisted of only 183 aa, while the other MPK16 members had 544 aa (Table S1). MPK21-2 had two branches, designated as type I and II (Table S6), indicating that it may have a certain functional divergence. In addition, MPK7-1 and MPK7-2 were located on same branch with a large discrepancy in their lengths (Figure 1), suggesting functional divergence, which is supported by previous functional studies (Jiang et al., 2015).

We analyzed a total of $618 \mathrm{MKKs}$ for their phylogenetic relationship with corresponding protein sequences using ML and NJ methods, respectively. Almost all of the orthologous genes for each of the $12 \mathrm{Bd} 21 \mathrm{MKKs}$ (BdMKKs) had similar clustering patterns with corresponding branches. The exceptions fell into four groups: A, B, C, and D (Figures 2, S4 and S5). However, BdTR10cMKK10-3, Jer1MKK10-4, Mur1MKK10-5, and BdTR13cMKK10-5 were branched out from the other members, suggesting that these gene members may have diverged (Figure 2). It is noteworthy that Mur1MKK10-5 (188 aa) and BdTR13cMKK10-5 (208 aa) had shorter amino acids than other members, which usually contained 332 aa (Table S2). BdTR10cMKK103 (163 aa) was also shorter relative to the normal MKK10-3 (344 aa). In contrast, Jer1MKK10-4 (424 aa) was longer when compared with the typical MKK10-4 (341 aa) (Table S2). These situations may affect their evolutionary relationship with MKKs from other B. distachyon inbred lines.

\section{Exon-intron compositions and length variations of MPKs and MKKs in B. distachyon inbred lines}

The abundance of non-protein-coding DNA within a genome, such as an intron, increased consistently with the genome complexity (Taft et al., 2007). Intron pattern analyses can enhance our understanding of the structure and evolution of genes (Zhang et al., 2014). We also surveyed

Peer] reviewing PDF | (2020:09:52464:3:0:NEW 6 Feb 2021) 
189

190

191

192

193

194

195

196

197

198

199

200

201

202

203

204

205

206

207

208

209

210

211

212

213

214

215

216

217

218

219

220

221

222

223

224

225

226

227

228

the exon-intron architecture of different MPKs and MKKs using GSDS software to elucidate the relationship or divergence among paralogues and orthologues. Most members showed similar exon-intron patterns with the intron number, exon length, and intron phase. The intron number was found to be relatively constant in three genetic groups, with the exceptions of MPK20-3, MPK21-2, and MKK3-3 (Figure 3). Remarkably, the number of introns from MPK11, MPK21-1, and MKK1 in all B. distachyon inbred lines consistently contained 5, 10, and 8 introns, respectively (Figure 3). Almost all MPK20-3 had three introns in group T+ apart from BdMPK20-3, Bd21-3MPK20-3, BdTR13aMPK20-3, BdTR3cMPK20-3, and Bd18-1MPK20-3 which had eight introns, while other two genetic groups of MPK20-3 displayed three or eight introns (Figures 3A and S6). Moreover, the number of introns of MKK3-3 was highly consistent in group $\mathrm{S}+$, and $\mathrm{T}+$ usually contained nine introns. In contrast, the intron numbers in group EDF+ were highly variable; for example, ABR9MKK3-3, Bd29-1MKK3-3, Tek-4MKK3-3 had eight, six, and four introns, respectively (Figures 3B and S7).

The exon-intron patterns of MPK21-2 fell into two groups, which coincided with their phylogenetic relationship mentioned above (Figures 1 and 4). However, the phylogenetic relationship was not completely consistent between the reconstructed full length coding sequence (CDS) and their exon-intron patterns (Figure 4). Further analysis showed that all type II MPK212s harbored UTRs, while type I MPK21-2s had no UTR except for RON2MPK21-2 and Tek4MPK21-2 (Figure 4). Most MPK21-2s had seven introns in group EDF+ and S+ or nine introns in group T+ except for BdMPK21-2, Bd3-1MPK21-2, and Adi-10MPK21-2 (Figure 3A). These results suggested that the structure and evolution of these genes were influenced by intron patterns and may be affected by UTRs.

\section{Common conserved domain analysis of $B$. distachyon MPKs and MKKs}

Previous research has reported that MAPKs had several conserved domains or signature sequences with vital structural or functional roles, including the GxGxxG motif in the nucleotide binding (NB) domain (Mohanta et al., 2015), the TXY motif in the activation loop (Xu and Zhang, 2015), D(I/L/V)K motif in the active site (Goyal et al., 2018), and the common docking (CD) domain in the C-terminal extension region outside the catalytic domain (Tanoue et al., 2000). Specifically, the threonine or tyrosine in the TXY motif as the activation loop plays pivotal roles in the signal transduction pathway. Remarkably, the average abundance of threonine or tyrosine (TXY), the most important enzymes in the B. distachyon inbred lines, were 4.67 and 3.91, respectively, and 4.62 and 3.81 in Bd21, respectively, (Table S7) suggesting that these amino acids were relatively constant. We also found that the conserved domains of eleven MPKs reported in comprehensive plant species were highly conserved in individual MPKs of $B$. distachyon inbred lines (Figures S8 and S9). These analyses revealed that the activation loop TEY in groups A, B, and C, and TDY in group D, were consistent with results from previous studies. Most notably, the activation loop TEY motif in all B. distachyon MPK11s was replaced by the MEY motif (Figure 1). MAPKs harbored a CD domain featuring a cluster of negativelycharged amino acids with consensus sequences M/L-L-A/V-F-D-P-X2-R-P/I-T/S-A/V-X-E-A-L (Figure 1) that bind the basic residues at the N-terminus of the docking site in MAPK-interaction 
229

230

231

232

233

234

235

236

237

238

239

240

241

242

243

244

245

246

247

248

249

250

251

252

253

254

255

256

257

258

259

260

261

262

263

264

265

266

267

proteins (Jiang et al., 2018). MPK7-2s belonged to leucine-rich repeat receptor kinases (LRRRKs) that had LRR domains and an NB-ARC domain, only appearing in seven kinds of $B$. distachyon inbred lines (Figure 1). Moreover, the DLK active site within the MPK7-1s signature was conserved; however, Luc1MPK7-1 and ABR6MPK7-1 were replaced with a DLN motif. Foz1MPK7-2 and Mur1MPK7-2 with DLN motifs were treated similarly (Figure S8). Specifically, all MPK11s had a DLR motif instead of a DLK active site (Figure S8). Furthermore, an elongation factor hand (EF-hand) calcium binding protein (CBP) with the consensus sequences "NDNNEQHASDQER" was observed in all B. distachyon MPK17s at their Cterminal end (Figures 1, 5A, and 5B). Further analysis indicated that 13 MPK17 members (group T+: BdTR13cMPK17, Bis-1MPK17, Bd21-3MPK17, BdMPK17, Adi-2MPK17 and BdTR13aMPK17; group EDF+: Tek-2MPK17, Tek-4MPK17, Bd29-1MPK17, ABR9MPK17, BdTR8iMPK17, BdTR7aMPK17, and Bd1-1MPK17) had a mutation in which E changed to D, which only resulted from a single nucleotide substitution of A changed to $\mathrm{C}$ (Figure 5C). This mutation may be have no effect on the function due to the canonical EF-hand (for example the calcineurin B-like (CBL) protein), that are characterized by a conserved Asp (D) and Glu (E) residue with completely constant spacing (Kolukisaoglu et al., 2004; Jiang et al., 2020). Remarkably, the MPK17s exhibited the conserved domain specific to B. distachyon members compared to other plant species, especially eudicots (Figure 5D).

As same as the MAPKs, MKKs also contained some important domains or motifs including the activation or T-loop S/T-X $-\mathrm{S} / \mathrm{T}$ motif (Asai et al., 2002), the docking site $\left(\mathrm{K} / \mathrm{R}_{2-3} \mathrm{X}_{1-5} \mathrm{~L} / \mathrm{IXL} / \mathrm{I}\right)$ in the N-terminal domain (Bardwell and Shah, 2006; Jiang and Chu, 2018), the GxGxxGxV motif

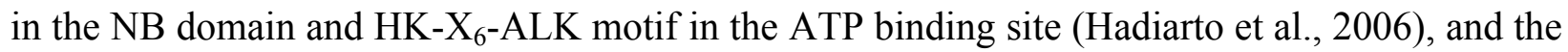
active site $\mathrm{D}(\mathrm{I} / \mathrm{L} / \mathrm{V}) \mathrm{K}$ motif (Goyal et al., 2018). A detailed analysis of the conserved sequences of MKKs was displayed in alignment of individual MKKs (Figures S10 and S11). Groups A, B, and $\mathrm{C}$ MKKs had the typical T-loop S/T-X 5 -S/T motif, while group D MKKs (MKK10s) had a part mutation in the phosphorylation site which coincided with a wide range of plant species (Figures 2 and S10) (Jiang and Chu, 2018). Interestingly, the average abundance of serine or threonine $\left(\mathrm{S} / \mathrm{T}-\mathrm{X}_{5}-\mathrm{S} / \mathrm{T}\right)$, which were the most crucial amino acids in $B$. distachyon inbred lines, were 7.2 and 3.32, respectively, while the same results were 7.2 and 3.32 in Bd21 (Table S7), respectively. This suggests that these amino acids remained constant. We speculated that the MKKs may have experienced fundamental functional conservation. Further analysis showed that variations of some the conserved MKKs were also present. For instance, in addition to BdTR13CMKK4 being replaced by a DIL motif, the $\mathrm{D}(\mathrm{I} / \mathrm{L} / \mathrm{V}) \mathrm{K}$ active site within the signature of MKKs was conserved despite occasional variations (Figure S10). We found the HRPTGRCYALK motif in the ATP binding site of MKK5 members, however, BdTR3cMKK5 was replaced by the HRPPGRCYALK motif (Figure S10). Furthermore, our data showed that the nuclear transport factor 2 (NTF2) domains existed in all MKK3s from B. distachyon inbred lines (Figure 2).

\section{The differential evolution of $M K K 10$ paralogs with tandem duplications}


268 Gene duplication was the necessary material source for evolutionary novelty, leading to the gene 269 responsible for the gene families (Lynch and Conery, 2000). In addition, some tandem 270 duplication was observed in monocot MKK10 paralogues, such as in B. distachyon (Jiang and 271 Chu, 2018). A 6,7-dimethyl-8-ribityllumazine (DMRL) synthase gene was observed between two $272 M K K$ members (Jiang and Chu, 2018). We surveyed the duplicated genes in different $B$. 273 distachyon inbred lines genome to further comprehend the duplication and evolutionary events of 274 the $B$. distachyon MKK10 paralogues. As expected, most of MKK10 paralogues with the 275 exception of five kinds of $B$. distachyon inbred lines (Mon3, Bd3-1, Adi-10, BdTR10c, and Gaz276 8) presented tandem duplication in the canonical form of the $M K K-D M R L-M K K$ model with 277 occasional variations (Figure 6). In addition, Tek-4 had the $P N N$ (pinin) gene instead of the $278 D M R L$ gene between two $M K K$ gene members (Figure 6). Twenty $B$. distachyon inbred lines had 279 the same canonical model with $\mathrm{Bd} 21$ in the form of the $M K K-D M R L-M K K-M K K$ model. Eight $B$. 280 distachyon inbred lines possessed the tandem duplication in the form of the $M K K-D M R L-M K K$ 281 model (Figure 6). Moreover, some small variations were also found in other B. distachyon inbred 282 lines. For example, we also found the tandem gene clusters with the MKK-DMRL-UDPGTUDPGT-MKK (UDPGT: UDP-glucoronosyl and UDP-glucosyl transferase) model in Mur1, $M K K-D M R L-M K K-C h a C-M K K$ (ChaC: ChaC-like protein) model in BdTR12c, and $M K K-$ $D M R L-P K-P K-M K K$ ( $P K$ : protein tyrosine kinase) model in Sig2 (Figure 6). These results indicated that the tandem $M K K 10$ gene clusters in $B$. distachyon inbred lines originated in the common ancestral genomic contexts and a certain variation developed in order to adapt to the environment differences including light, temperature, or elevation.

\section{Expression variation in the $M P K$ and $M K K$ gene family in three selected genomes}

290

291

292

293

294

295

296

297

298

299

300

301

302

303

304

305

306

307

The expression profiles for five different tissues (root, stem, leaf blade, leaf sheath, and spikelet) and abiotic stresses (salt, drought, and heat) of $M P K$ and $M K K$ genes were performed (Table S8) to explore the expression variation of the $M P K$ and $M K K$ gene family in $\mathrm{Bd} 21$, BdTR8i, and Bd30-1. These families belong to three different genetic groups. We observed the different expression levels of $15 M P K$ and $11 M K K$ genes apart from the MKK10-4 gene (Figures 7 and 8), which may be involved with the barely detectable low expression level of the MKK10-4 gene observed in previous research (Jiang and Chu, 2018). Among these $M P K$ and $M K K$ genes, most genes showed distinct quantitative expression patterns in their different genetic backgrounds. For instance, the expression level of $M P K 4 s$ at root was higher in BdTR8i and moderate in Bd21 compared with in Bd30-1 (Figure 7). $M P K 3 s$ had the same reaction after $6 \mathrm{~h}$ of drought treatment (Figure 8). MKK10-3s had higher expression in spikelet's in BdTR8i compared with in $\mathrm{Bd} 21$ and Bd30-1 (Figure 7). Moreover, these genes also had similar expression patterns in different genetic backgrounds, such as MPK16s, MPK20-4s, MKK3-2s, and MKK10-1s in spikelet, $M K K 5 s$ in leaf sheath, MPK6s and MKK10-2s in leaf blade, MPK16s and MKK10-5s in stem, MPK16s, and MPK20-5s and MKK10-1s in root (Figure 7). MKK4s had a higher expression under drought conditions in BdTR8i compared with in $\mathrm{Bd} 21$ and $\mathrm{Bd} 30-1$ (Figure 8). $M P K 3 s$ had a relatively low expression under heat treatment in three backgrounds, while the expressions of $M P K 14 s$ and $M P K 20-1 s$ were opposite (Figure 8). Expression variations were 
308

309

310

311

312

313

314

315

316

317

318

319

320

321

322

323

324

325

326

327

328

329

330

331

332

333

334

335

336

337

338

339

340

341

342

343

344

345

346

also observed in the different tissues and/or abiotic stresses. For example, MKK10-1s were more highly expressed in three genetic backgrounds in roots than in other tissues (Figure 7). Almost all genes had higher expression levels after $6 \mathrm{~h}$ of exposure to three abiotic stresses in BdTR8i (Figure 8). We further found that certain genes had unique expression profiles in specific tissues of a particular genetic background. For example, BdTR8iMPK4 was highly expressed in only the root (Figure 7) and BdTR8iMKK1 was highly expressed in heat, salt, and drought stresses (Figure 8). The striking variations of $M P K$ and $M K K$ gene family members expressed in different genetic contexts increases the diversity of the potential biological functions of these genes.

\section{Discussion}

\section{Exon-intron compositions with conservative and divergent patterns}

The conservation of exon length was associated with constraints of the gene function of organisms (Davila-Velderrain et al., 2014). The non-coding regions, such as the intron, may affect gene functions by a gradual deletion, which may be the result of recombination throughout the evolution of the intron $(\mathrm{Hu}, 2006)$. Therefore, we investigated the exon-intron composition of the corresponding $M P K s$ and $M K K s$. Our results showed that the exon-intron architecture, including lengths and numbers of intron, intron phase, and lengths of UTR, was generally conserved in corresponding orthologs (Figures S6 and S7). However, some variability was also found. For example, type II MPK21-2s harbored 5'-UTR and 3'-UTR which were absent in type I MPK21-2s (Figure 4), although they were in agreement with their phylogenetic relationships (Figure 1), indicating that they may have a difference in expression and functional divergence. The UTR length-dependent functional specificity significantly increases the coding capacity of the genome that regulates multiple plant process, including nutrient homeostasis, stress responses, and plant growth and development (Srivastava et al., 2018). In addition, there was a large difference in the intron lengths and numbers among $B$. distachyon MPK7-1s and MPK20-3s (Figure S6). A detailed analysis showed that the fourth intron of BdTR8iMPK20-3 was shorter than BdMPK20-3 and Bd30-1MPK20-3 (Figure S6). Moreover, BdTR8iMPK20-3 had a lower expression level in roots and spikelets compared to the other corresponding members as described in a previous study that intron lengths were correlated with gene expression (Rose et al., 2016). Our findings indicated that the exon-intron composition affect the evolutionary patterns and expression efficiency of $M P K$ and $M K K$ orthologs.

\section{Tandem duplications contributed to MKK10s gene expansion}

Our analysis suggested that MKK10 paralogs undergo an ancient tandem duplication event with differential evolution. Further examination of tandem MKK10 gene clusters revealed that a $D M R L$ gene often occurred (Figure 6). These results are supported by previous studies (Jiang and $\mathrm{Chu}$, 2018), indicating that they were derived from common ancestral genomic contexts. However, some variations have also been found among $B$. distachyon inbred lines such as an insertion of $R R M$ (RNA recognition motif protein) instead of the DMRL gene (Figure 6). This may result in a difference of gene expression. Indeed, tandem duplicates generally show more similar expression patterns than remote duplicates (Dai et al., 2014, Lan and Pritchard, 2016) and 
347 preferentially retain the cis-PPIs (protein-protein interactions) after WGD (Makino and 348 McLysaght, 2008, 2012). Therefore, ancient tandem duplications of MKK10s may have 349 contributed to gene expansion and function conservation and/or divergence during the evolution 350 process of monocots.

\section{Expression divergence of $M A P K s$ and $M K K s$ within three $B$. distachyon genetic groups}

352 Tissue-specific expression patterns of $M A P K$ and $M K K$ genes have been characterized with

353

354

355

356

357

358

359

360

361

362

363

364

365

366

367

368

369

370

371

372

373

374

375

376

377

378

379

380

381

382

383

384

corresponding functions in plant growth and development. For instance, the expression levels of AtMKK10 are high in pollen but do not appear in shoot apices, mesophyll cells, or mature leaves (Yoo et al., 2008), indicating a potential role in flower tissues (Jiang and Chu, 2018). CaMPK192 genes are highly expressed in roots and stems in pepper, while CaMPK1 is highly expressed in in leaves (Liu et al., 2015), which indicates that these genes are expressed preferentially in different tissues and developmental stages (Wei et al., 2014). We investigated the tissue-specific expression profiles in different $B$. distachyon inbred lines. The result indicated that most $M P K$ and $M K K$ genes had quantitative distinct expression patterns among the three different genetic contexts in different tissues and various abiotic stresses. For example, MPK17 had higher expression levels in the root, stem, leaf blade, and salt treatment in Bd30-1 compared with Bd21 and BdTR8i (Figures 7 and 8). These results are indicative of the distinct function of MPK17s, which may result from the nonsynonymous substitutions at some pivotal amino acid sites in EFhand CBP motif in their C-terminal extensions (Figure 5) as described previously (Yang et al., 2019). Moreover, MKK10-3 and MKK10-5 had similar expression patterns in the leaf blade in Bd30-1 and BdTR8i and distinct profiles in Bd21 (Figure 7). These results coincide with the tandem gene cluster model (Figure 6) and are supported by previous reports that physically linked genes (tandem duplicates) usually had less expression differences than distant genes (Ghanbarian and Hurst, 2015; Lan and Pritchard, 2016). Furthermore, the $M K K 3-2$ gene had similar patterns under heat and salt condition (Figure 8). Taken together, these results suggest that $M A P K s$ and $M K K s$ had an expression divergence which was correlated with the differential evolution in $B$. distachyon inbred lines.

\section{Conclusion}

A total of $799 M P K$ and $618 M K K$ genes were retrieved from 53 kinds of B. distachyon inbred lines based on their conserved TXY or $\mathrm{S} / \mathrm{T}-\mathrm{X}_{5}-\mathrm{S} / \mathrm{T}$ domain, respectively, using bioinformatics approaches. Phylogenetic analyses showed that most MAPKs and MKKs clustered into same branch, with the exception of MPK21-2s, which was divided into two groups, designated as type I and II. Further analysis found that the divergence of MPK21-2 may be involved with the presence of UTRs. MKK10s expanded during the evolutionary process by ancient tandem duplications with a differential model. This may have resulted in expression differences and functional divergence. We discovered that the expression of the $M P K$ and $M K K$ gene members varied in different tissues and across abiotic stresses in three different genetic contexts, suggesting that these genes may have diverse biological functions. Taken together, our results

Peer] reviewing PDF | (2020:09:52464:3:0:NEW 6 Feb 2021) 
385

386

387

388

389

390

391

392

393

394

395

396

397

398

399

400

401

402

403

404

405

406

407

408

409

410

411

412

413

414

415

416

417

418

419

420

421

422

423

424

revealed a more comprehensive understanding of the function and evolutionary patterns of MAPKs and MKKs in diverse $B$. distachyon inbred lines.

\section{References}

Altschul, SF, Madden, TL, Schaffer, AA, Zhang, JH, Zhang, Z, Miller, W, and Lipman, DJ. 1997. Gapped BLAST and PSI-BLAST: a new generation of protein database search programs. Nucleic Acids Research 25:3389-3402.

Asai, T, Tena, G, Plotnikova, J, Willmann, MR, Chiu, WL, Gomez-Gomez, L, Boller, T, Ausubel, FM, and Sheen, J. 2002. MAP kinase signalling cascade in Arabidopsis innate immunity. Nature 415:977-983.

Bardwell, L, and Shah, K. 2006. Analysis of mitogen-activated protein kinase activation and interactions with regulators and substrates. Methods 40:213-223.

Brkljacic, J, Grotewold, E, Scholl, R, Mockler, T, Garvin, DF, Vain, P, Brutnell, T, Sibout, R, Bevan, M, Budak, H, Caicedo, AL, Gao, CX, Gu, Y, Hazen, SP, Holt, BF, Hong, SY, Jordan, M, Manzaneda, AJ, Mitchell-Olds, T, Mochida, K, Mur, LAJ, Park, CM, Sedbrook, J, Watt, M, Zheng, SJ, and Vogel, JP. 2011. Brachypodium as a Model for the Grasses: Today and the Future. Plant Physiology 157:3-13.

Catalan, P, Chalhoub, B, Chochois, V, Garvin, DF, Hasterok, R, Manzaneda, AJ, Mur, LAJ, Pecchioni, N, Rasmussen, SK, Vogel, JP, and Voxeur, A. 2014. Update on the genomics and basic biology of Brachypodium International Brachypodium Initiative (IBI). Trends in Plant Science 19:414-418.

Catalan, P, Lopez-Alvarez, D, Bellosta, C, and Villar, L. 2016. Updated taxonomic descriptions, iconography, and habitat preferences of Brachypodium distachyon, B-stacei, and B-hybridum (Poaceae). Anales Del Jardin Botanico De Madrid 73:e028.

Chen, LH, Hu, W, Tan, SL, Wang, M, Ma, ZB, Zhou, SY, Deng, XM, Zhang, Y, Huang, C, Yang, GX, and He, GY. 2012. Genome-Wide Identification and Analysis of MAPK and MAPKK Gene Families in Brachypodium distachyon. Plos One 7:e46744.

Cuevas, HE, Zhou, CB, Tang, HB, Khadke, PP, Das, S, Lin, YR, Ge, ZX, Clemente, T, Upadhyaya, HD, Hash, CT, and Paterson, AH. 2016. The Evolution of Photoperiod-Insensitive Flowering in Sorghum, A Genomic Model for Panicoid Grasses. Molecular Biology and Evolution 33:2417-2428.

Dai, ZM, Xiong, YY, and Dai, XH. 2014. Neighboring Genes Show Interchromosomal Colocalization after Their Separation. Molecular Biology and Evolution 31:1166-1172.

Davila-Velderrain, J, Servin-Marquez, A, and Alvarez-Buylla, ER. 2014. Molecular Evolution Constraints in the Floral Organ Specification Gene Regulatory Network Module across 18 Angiosperm Genomes. Molecular Biology and Evolution 31:560-573.

Draper, J, Mur, LAJ, Jenkins, G, Ghosh-Biswas, GC, Bablak, P, Hasterok, R, and Routledge, APM. 2001. Brachypodium distachyon. A new model system for functional genomics in grasses. Plant Physiology 127:1539-1555.

Filiz, E, Ozdemir, BS, Budak, F, Vogel, JP, Tuna, M, and Budak, H. 2009. Molecular, morphological, and cytological analysis of diverse Brachypodium distachyon inbred lines. Genome 52:876-890.

Freeling, M. 2009. Bias in Plant Gene Content Following Different Sorts of Duplication: Tandem, Whole-Genome, Segmental, or by Transposition. Annual Review of Plant Biology 60:433-453.

Garvin, DF, Gu, YQ, Hasterok, R, Hazen, SP, Jenkins, G, Mockler, TC, Mur, LAJ, and Vogel, JP. 2008. Development of genetic and genomic research resources for Brachypodium distachyon, a new model system for grass crop research. Crop Science 48:S69-S84.

Peer) reviewing PDF | (2020:09:52464:3:0:NEW 6 Feb 2021) 
Ghanbarian, AT, and Hurst, LD. 2015. Neighboring Genes Show Correlated Evolution in Gene Expression. Molecular Biology and Evolution 32:1748-1766.

Gordon, SP, Contreras-Moreira, B, Woods, DP, Marais, DLD, Burgess, D, Shu, SQ, Stritt, C, Roulin, AC, Schackwitz, W, Tyler, L, Martin, J, Lipzen, A, Dochy, N, Phillips, J, Barry, K, Geuten, K, Budak, H, Juenger, TE, Amasino, R, Caicedo, AL, Goodstein, D, Davidson, P, Mur, LAJ, Figueroa, M, Freeling, M, Catalan, P, and Vogel, JP. 2017. Extensive gene content variation in the Brachypodium distachyon pan-genome correlates with population structure. Nature Communications 8:2184.

Gordon, SP, Priest, H, Marais, DLD, Schackwitz, W, Figueroa, M, Martin, J, Bragg, JN, Tyler, L, Lee, CR, Bryant, D, Wang, WQ, Messing, J, Manzaneda, AJ, Barry, K, Garvin, DF, Budak, H, Tuna, M, Mitchell-Olds, T, Pfender, WF, Juenger, TE, Mockler, TC, and Vogel, JP. 2014. Genome diversity in Brachypodium distachyon: deep sequencing of highly diverse inbred lines. Plant Journal 79:361-374.

Goyal, RK, Tulpan, D, Chomistek, N, Fundora, DGP, West, C, Ellis, BE, Frick, M, Laroche, A, and Foroud, NA. 2018. Analysis of MAPK and MAPKK gene families in wheat and related Triticeae species. BMC Genomics 19:178.

Guan, YF, Meng, XZ, Khanna, R, LaMontagne, E, Liu, YD, and Zhang, SQ. 2014. Phosphorylation of a WRKY Transcription Factor by MAPKs Is Required for Pollen Development and Function in Arabidopsis. Plos Genetics 10:e1004384.

Hadiarto, T, Nanmori, T, Matsuoka, D, Iwasaki, T, Sato, K, Fukami, Y, Azuma, T, and Yasuda, T. 2006. Activation of Arabidopsis MAPK kinase kinase (AtMEKK1) and induction of AtMEKK1-AtMEK1 pathway by wounding. Planta 223:708-713.

Hu, KJ. 2006. Intron exclusion and the mystery of intron loss. Febs Letters 580:6361-6365.

Ichimura, K, Shinozaki, K, Tena, G, Sheen, J, Henry, Y, Champion, A, Kreis, M, Zhang, SQ, Hirt, H, Wilson, C, HeberleBors, E, Ellis, BE, Morris, PC, Innes, RW, Ecker, JR, Scheel, D, Klessig, DF, Machida, Y, Mundy, J, Ohashi, Y, Walker, JC, and Grp, M. 2002. Mitogen-activated protein kinase cascades in plants: a new nomenclature. Trends in Plant Science 7:301-308.

Jagodzik, P, Tajdel-Zielinska, M, Ciesla, A, Marczak, M, and Ludwikow, A. 2018. Mitogen-Activated Protein Kinase Cascades in Plant Hormone Signaling. Frontiers in Plant Science 9:1387.

Jiang, M, and Chu, ZQ. 2018. Comparative analysis of plant MKK gene family reveals novel expansion mechanism of the members and sheds new light on functional conservation. BMC Genomics 19:407.

Jiang, M, Niu, C, Cao, JM, Ni, DA, and Chu, ZQ. 2018. In silico-prediction of protein-protein interactions network about MAPKs and PP2Cs reveals a novel docking site variants in Brachypodium distachyon. Scientific Reports 8:15083.

Jiang, M, Wen, F, Cao, JM, Li, P, She, J, and Chu, ZQ. 2015. Genome-wide exploration of the molecular evolution and regulatory network of mitogen-activated protein kinase cascades upon multiple stresses in Brachypodium distachyon. BMC Genomics 16:228.

Jiang, M, Zhao, CL, Zhao, MF, Li, YZ, and Wen, GS. 2020. Phylogeny and Evolution of Calcineurin B-Like (CBL) Gene Family in Grass and Functional Analyses of Rice CBLs. Journal of Plant Biology 63:117-130.

Jones, P, Binns, D, Chang, HY, Fraser, M, Li, WZ, McAnulla, C, McWilliam, H, Maslen, J, Mitchell, A, Nuka, G, Pesseat, S, Quinn, AF, Sangrador-Vegas, A, Scheremetjew, M, Yong, SY, Lopez, R, and Hunter, S. 2014. InterProScan 5: genome-scale protein function classification. Bioinformatics 30:1236-1240.

Joo, S, Liu, Y, Lueth, A, and Zhang, SQ. 2008. MAPK phosphorylation-induced stabilization of ACS6 protein is mediated by the non-catalytic C-terminal domain, which also contains the cis-determinant for rapid

Peer] reviewing PDF | (2020:09:52464:3:0:NEW 6 Feb 2021) 
degradation by the 265 proteasome pathway. Plant Journal 54:129-140.

Kolukisaoglu, U, Weinl, S, Blazevic, D, Batistic, O, and Kudla, J. 2004. Calcium sensors and their interacting protein kinases: Genomics of the Arabidopsis and rice CBL-CIPK signaling networks. Plant Physiology 134:43-58.

Lan, X, and Pritchard, JK. 2016. Coregulation of tandem duplicate genes slows evolution of subfunctionalization in mammals. Science 352:1009-1013.

Liu, ZQ, Shi, LP, Liu, YY, Tang, Q, Shen, L, Yang, S, Cai, JS, Yu, HX, Wang, RZ, Wen, JY, Lin, YQ, Hu, J, Liu, CL, Zhang, YW, Mou, SL, and He, SL. 2015. Genome-wide identification and transcriptional expression analysis of mitogen-activated protein kinase and mitogen-activated protein kinase kinase genes in Capsicum annuum. Frontiers in Plant Science 6:780.

Lynch, M, and Conery, JS. 2000. The evolutionary fate and consequences of duplicate genes. Science 290:11511155.

Makino, T, and McLysaght, A. 2008. Interacting gene clusters and the evolution of the vertebrate immune system. Molecular Biology and Evolution 25:1855-1862.

Makino, T, and McLysaght, A. 2012. Positionally biased gene loss after whole genome duplication: Evidence from human, yeast, and plant. Genome Research 22:2427-2435.

Mitchell, AL, Attwood, TK, Babbitt, PC, Blum, M, Bork, P, Bridge, A, Brown, SD, Chang, HY, El-Gebali, S, Fraser, MI, Gough, J, Haft, DR, Huang, HZ, Letunic, I, Lopez, R, Luciani, A, Madeira, F, Marchler-Bauer, A, Mi, HY, Natale, DA, Necci, M, Nuka, G, Orengo, C, Pandurangan, AP, Paysan-Lafosse, T, Pesseat, S, Potter, SC, Qureshi, MA, Rawlings, ND, Redaschi, N, Richardson, L, Rivoire, C, Salazar, GA, Sangrador-Vegas, A, Sigrist, CJA, Sillitoe, I, Sutton, GG, Thanki, N, Thomas, PD, Tosatto, SCE, Yong, SY, and Finn, RD. 2019. InterPro in 2019: improving coverage, classification and access to protein sequence annotations. Nucleic Acids Research 47:D351-D360.

Mohanta, TK, Arora, PK, Mohanta, N, Parida, P, and Bae, H. 2015. Identification of new members of the MAPK gene family in plants shows diverse conserved domains and novel activation loop variants. BMC Genomics 16:58.

Mur, LAJ, Allainguillaume, J, Catalan, P, Hasterok, R, Jenkins, G, Lesniewska, K, Thomas, I, and Vogel, J. 2011. Exploiting the Brachypodium Tool Box in cereal and grass research. New Phytologist 191:334-347.

Paterson, AH, Freeling, M, Tang, HB, and Wang, XY. 2010. Insights from the Comparison of Plant Genome Sequences. Annual Review of Plant Biology 61:349-372.

Qiao, X, Li, QH, Yin, H, Qi, KJ, Li, LT, Wang, RZ, Zhang, SL, and Paterson, AH. 2019. Gene duplication and evolution in recurring polyploidization-diploidization cycles in plants. Genome Biology 20:38.

Rodriguez, MCS, Petersen, M, and Mundy, J. 2010. Mitogen-Activated Protein Kinase Signaling in Plants. Annual Review of Plant Biology 61:621-649.

Rose, AB, Carter, A, Korf, I, and Kojima, N. 2016. Intron sequences that stimulate gene expression in Arabidopsis. Plant Molecular Biology 92:337-346.

Sancho, R, Cantalapiedra, CP, Lopez-Alvarez, D, Gordon, SP, Vogel, JP, Catalan, P, and Contreras-Moreira, B. 2018. Comparative plastome genomics and phylogenomics of Brachypodium: flowering time signatures, introgression and recombination in recently diverged ecotypes. New Phytologist 218:1631-1644.

Singh, R, Lee, MO, Lee, JE, Choi, J, Park, JH, Kim, EH, Yoo, RH, Cho, JI, Jeon, JS, Rakwal, R, Agrawal, GK, Moon, JS, and Jwa, NS. 2012. Rice Mitogen-Activated Protein Kinase Interactome Analysis Using the Yeast TwoHybrid System. Plant Physiology 160:477-487. 
Soltis, DE, Albert, VA, Leebens-Mack, J, Bell, CD, Paterson, AH, Zheng, CF, Sankoff, D, dePamphilis, CW, Wall, PK, and Soltis, PS. 2009. Polyploidy and Angiosperm Diversification. American Journal of Botany 96:336-348.

Soreng, RJ, Peterson, PM, Romaschenko, K, Davidse, G, Zuloaga, FO, Judziewicz, EJ, Filgueiras, TS, Davis, JI, and Morrone, O. 2015. A worldwide phylogenetic classification of the Poaceae (Gramineae). Journal of Systematics and Evolution 53:117-137.

Srivastava, AK, Lu, YM, Zinta, G, Lang, ZB, and Zhu, JK. 2018. UTR-Dependent Control of Gene Expression in Plants. Trends in Plant Science 23:248-259.

Taft, RJ, Pheasant, M, and Mattick, JS. 2007. The relationship between non-protein-coding DNA and eukaryotic complexity. Bioessays 29:288-299.

Tamura, K, Stecher, G, Peterson, D, Filipski, A, and Kumar, S. 2013. MEGA6: Molecular Evolutionary Genetics Analysis Version 6.0. Molecular Biology and Evolution 30:2725-2729.

Tanoue, T, Adachi, M, Moriguchi, T, and Nishida, E. 2000. A conserved docking motif in MAP kinases common to substrates, activators and regulators. Nature Cell Biology 2:110-116.

Vain, P, Worland, B, Thole, V, McKenzie, N, Opanowicz, M, Fish, L, Bevan, MW, and Snape, JW. 2008. Agrobacterium-mediated transformation of the temperate grass Brachypodium distachyon (genotype Bd21) for T-DNA insertional mutagenesis. Plant Biotechnology Journal 6:236-245.

Van Bel, M, Diels, T, Vancaester, E, Kreft, L, Botzki, A, Van de Peer, Y, Coppens, F, and Vandepoele, K. 2018. PLAZA 4.0: an integrative resource for functional, evolutionary and comparative plant genomics. Nucleic Acids Research 46:D1190-D1196.

Vogel, J, and Hill, T. 2008. High-efficiency Agrobacterium-mediated transformation of Brachypodium distachyon inbred line Bd21-3. Plant Cell Reports 27:471-478.

Vogel, JP, Garvin, DF, Mockler, TC, Schmutz, J, Rokhsar, D, Bevan, MW, Barry, K, Lucas, S, Harmon-Smith, M, Lail, K, Tice, H, Grimwood, J, McKenzie, N, Huo, NX, Gu, YQ, Lazo, GR, Anderson, OD, You, FM, Luo, MC, Dvorak, J, Wright, J, Febrer, M, Idziak, D, Hasterok, R, Lindquist, E, Wang, M, Fox, SE, Priest, HD, Filichkin, SA, Givan, SA, Bryant, DW, Chang, JH, Wu, HY, Wu, W, Hsia, AP, Schnable, PS, Kalyanaraman, A, Barbazuk, B, Michael, TP, Hazen, SP, Bragg, JN, Laudencia-Chingcuanco, D, Weng, YQ, Haberer, G, Spannagl, M, Mayer, K, Rattei, T, Mitros, T, Lee, SJ, Rose, JKC, Mueller, LA, York, TL, Wicker, T, Buchmann, JP, Tanskanen, J, Schulman, AH, Gundlach, H, de Oliveira, AC, Maia, LD, Belknap, W, Jiang, N, Lai, JS, Zhu, LC, Ma, JX, Sun, C, Pritham, E, Salse, J, Murat, F, Abrouk, M, Bruggmann, R, Messing, J, Fahlgren, N, Sullivan, CM, Carrington, JC, Chapman, EJ, May, GD, Zhai, JX, Ganssmann, M, Gurazada, SGR, German, M, Meyers, BC, Green, PJ, Tyler, L, Wu, JJ, Thomson, J, Chen, S, Scheller, HV, Harholt, J, Ulvskov, P, Kimbrel, JA, Bartley, LE, Cao, PJ, Jung, KH, Sharma, MK, Vega-Sanchez, M, Ronald, P, Dardick, CD, De Bodt, S, Verelst, W, Inze, D, Heese, M, Schnittger, A, Yang, XH, Kalluri, UC, Tuskan, GA, Hua, ZH, Vierstra, RD, Cui, Y, Ouyang, SH, Sun, QX, Liu, ZY, Yilmaz, A, Grotewold, E, Sibout, R, Hematy, K, Mouille, G, Hofte, H, Pelloux, J, O'Connor, D, Schnable, J, Rowe, S, Harmon, F, Cass, CL, Sedbrook, JC, Byrne, ME, Walsh, S, Higgins, J, Li, PH, Brutnell, T, Unver, T, Budak, H, Belcram, H, Charles, M, Chalhoub, B, Baxter, I, and Initiative, IB. 2010. Genome sequencing and analysis of the model grass Brachypodium distachyon. Nature 463:763-768.

Vogel, JP, Tuna, M, Budak, H, Huo, NX, Gu, YQ, and Steinwand, MA. 2009. Development of SSR markers and analysis of diversity in Turkish populations of Brachypodium distachyon. BMC Plant Biology 9:88.

Wang, XY, Gowik, U, Tang, HB, Bowers, JE, Westhoff, P, and Paterson, AH. 2009. Comparative genomic analysis of C4 photosynthetic pathway evolution in grasses. Genome Biology 10:R68. 
Wei, CJ, Liu, XQ, Long, DP, Guo, Q, Fang, Y, Bian, CK, Zhang, DY, Zeng, QW, Xiang, ZH, and Zhao, AC. 2014. Molecular cloning and expression analysis of mulberry MAPK gene family. Plant Physiology and Biochemistry 77:108-116.

$\mathrm{Xu}, \mathrm{J}$, and Zhang, SQ. 2015. Mitogen-activated protein kinase cascades in signaling plant growth and development. Trends in Plant Science 20:56-64.

Yang, Q, Han, XM, Gu, JK, Liu, YJ, Yang, MJ, and Zeng, QY. 2019. Functional and structural profiles of GST gene family from three Populus species reveal the sequence-function decoupling of orthologous genes. New Phytologist 221:1060-1073.

Yoo, SD, Cho, YH, Tena, G, Xiong, Y, and Sheen, J. 2008. Dual control of nuclear EIN3 by bifurcate MAPK cascades in C2H4 signalling. Nature 451:789-U781.

Zhang, GJ, Li, C, Li, QY, Li, B, Larkin, DM, Lee, C, Storz, JF, Antunes, A, Greenwold, MJ, Meredith, RW, Odeen, A, Cui, J, Zhou, Q, Xu, LH, Pan, HL, Wang, ZJ, Jin, LJ, Zhang, P, Hu, HF, Yang, W, Hu, J, Xiao, J, Yang, ZK, Liu, Y, Xie, QL, Yu, H, Lian, JM, Wen, P, Zhang, F, Li, H, Zeng, YL, Xiong, ZJ, Liu, SP, Zhou, L, Huang, ZY, An, N, Wang, J, Zheng, QM, Xiong, YQ, Wang, GB, Wang, B, Wang, JJ, Fan, Y, da Fonseca, RR, Alfaro-Nunez, A, Schubert, M, Orlando, L, Mourier, T, Howard, JT, Ganapathy, G, Pfenning, A, Whitney, O, Rivas, MV, Hara, E, Smith, J, Farre, M, Narayan, J, Slavov, G, Romanov, MN, Borges, R, Machado, JP, Khan, I, Springer, MS, Gatesy, J, Hoffmann, FG, Opazo, JC, Hastad, O, Sawyer, RH, Kim, H, Kim, KW, Kim, HJ, Cho, S, Li, N, Huang, YH, Bruford, MW, Zhan, XJ, Dixon, A, Bertelsen, MF, Derryberry, E, Warren, W, Wilson, RK, Li, SB, Ray, DA, Green, RE, O'Brien, SJ, Griffin, D, Johnson, WE, Haussler, D, Ryder, OA, Willerslev, E, Graves, GR, Alstrom, P, Fjeldsa, J, Mindell, DP, Edwards, SV, Braun, EL, Rahbek, C, Burt, DW, Houde, P, Zhang, Y, Yang, HM, Wang, J, Jarvis, ED, Gilbert, MTP, Wang, J, and Consortium, AG. 2014. Comparative genomics reveals insights into avian genome evolution and adaptation. Science 346:1311-1320. 


\section{Figure 1}

Phylogenetic distribution of 799 MPKs among diverse $B$. distachyon inbredlines.

MPKs are divided into four clades (A, B, C and D). Unique to $B$. distachyon MPK17s, an EFhand CBP domain is found in their C-terminal extensions. The group A, B and C carry TEY Tloops and group D MPKs carry TDY motifs, with the exception of MPK11s which carry an MEY motif. The CD domain is conserved in the MAPK family. The negatively charged amino acids ( $D$ and $E$ ) are expected to be exposed to the surface of the molecules. MPK7-2 also contained NB-ARC domain and LRR domain. NB: nucleotide-binding; LRR: leucine-rich repeat. ARC: APAF-1, R gene and CED-4. 


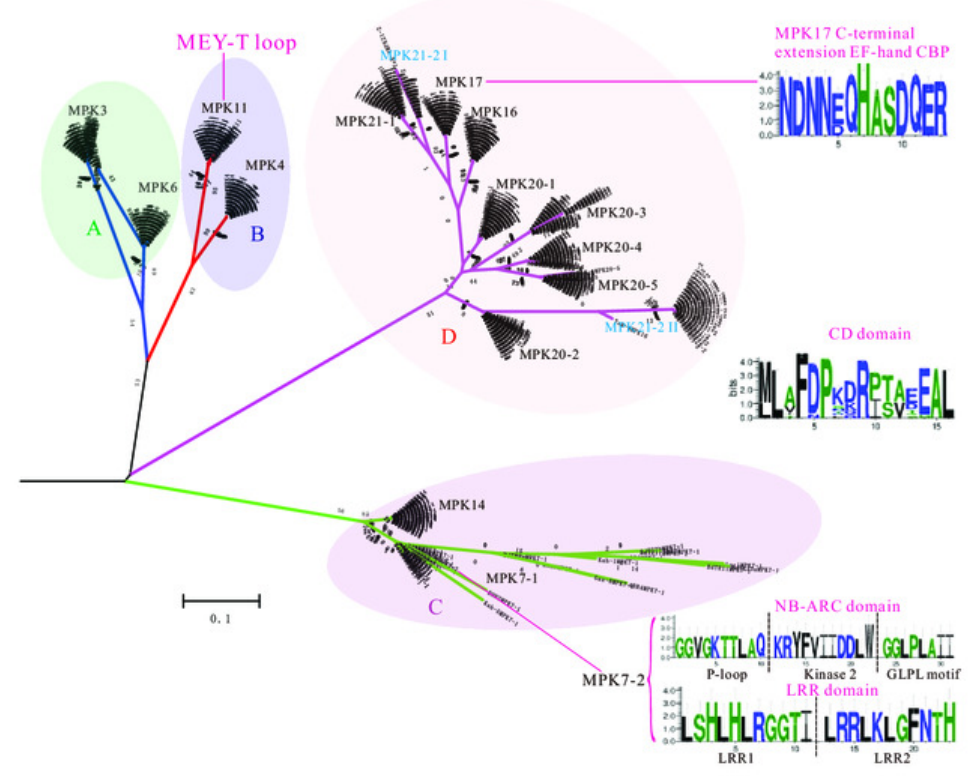




\section{Figure 2}

Phylogenetic distribution of 618 MKKs among diverse $B$. distachyoninbredlines

MKKs are divided into four clades ( $, B, C$ and D). Sequence features shown in the form of web logos representing the NTF-2 domain conserved in the C-terminal extensions of MKK3s. Web logos analysis shows amino acid distribution of conserved $\mathrm{S} / \mathrm{T}-\mathrm{X}_{5}-\mathrm{S} / \mathrm{T}$ motif in MKKS (groups $\mathrm{A}, \mathrm{B}$ and $\mathrm{C}$ ) and the docking site conserved in N-terminal extension of MKKs. 


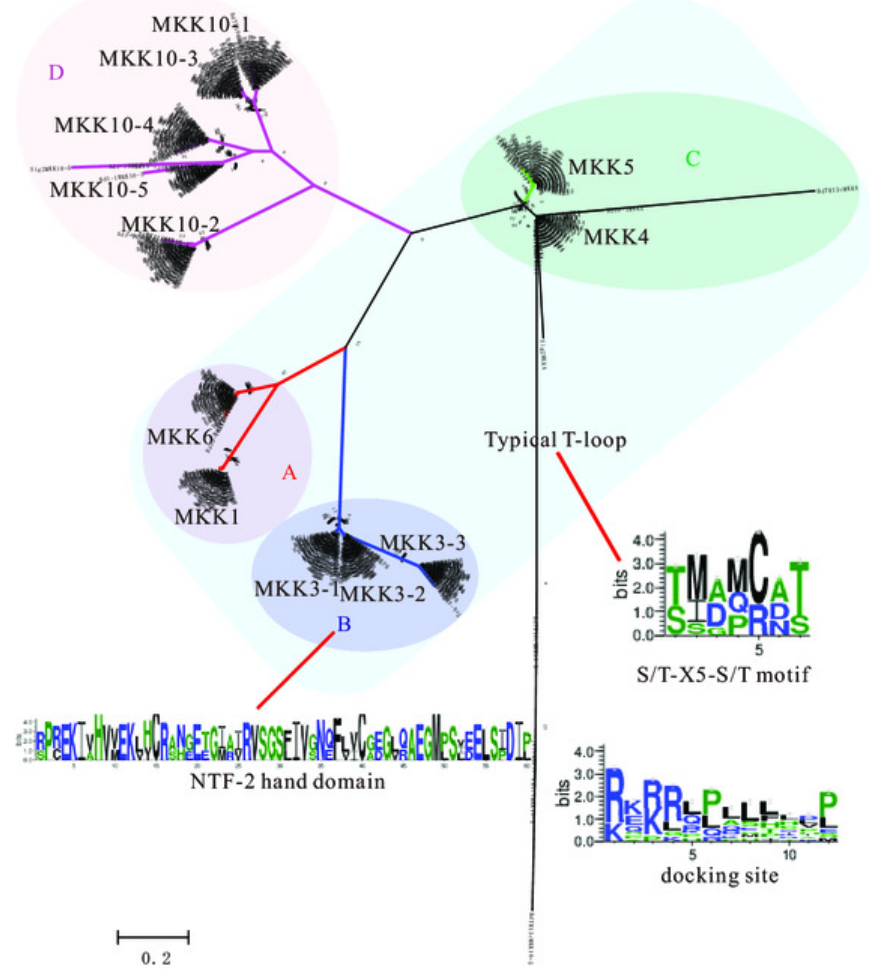


Figure 3

Introns number polymorphisms of MPKs from 53 diverse $B$. distachyon inbred lines

Different colors represent different genomic groups.

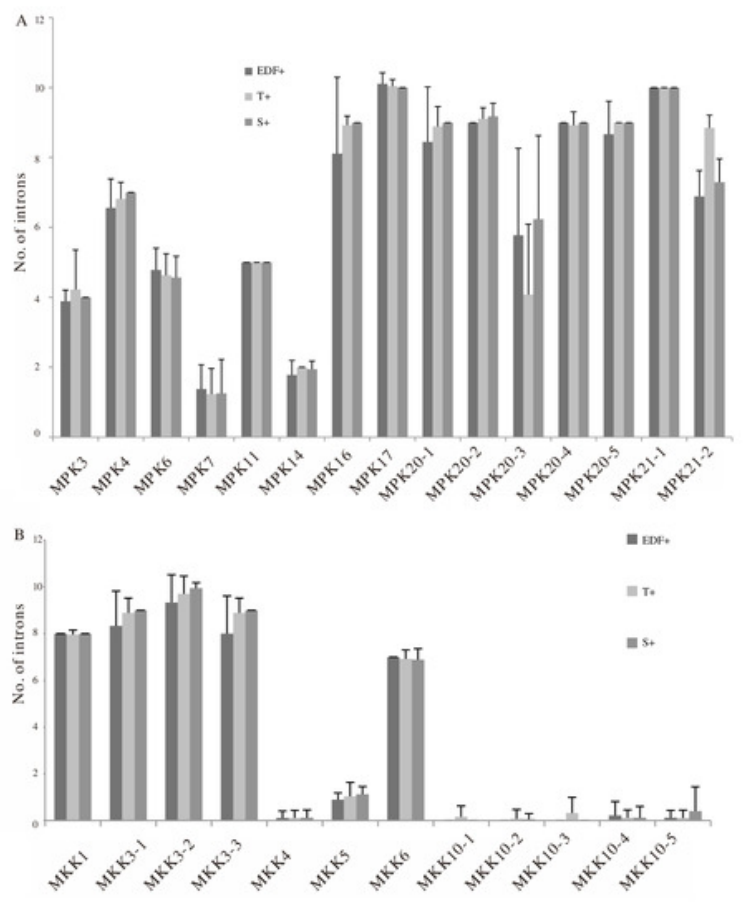


Figure 4

Gene structure of MPK21-2 genes.

(A) Maximum Likelihood phylogenetic trees of the full CDS sequences of genes encoding

MPK21-2 from diverse $B$. distachyon inbred lines. (B) The exon/intron structure of each

MPK21-2 gene was displayed. Yellow boxes represent exons, gray lines represent introns and blue boxes represent UTRs. The exons are drawn to scale. 


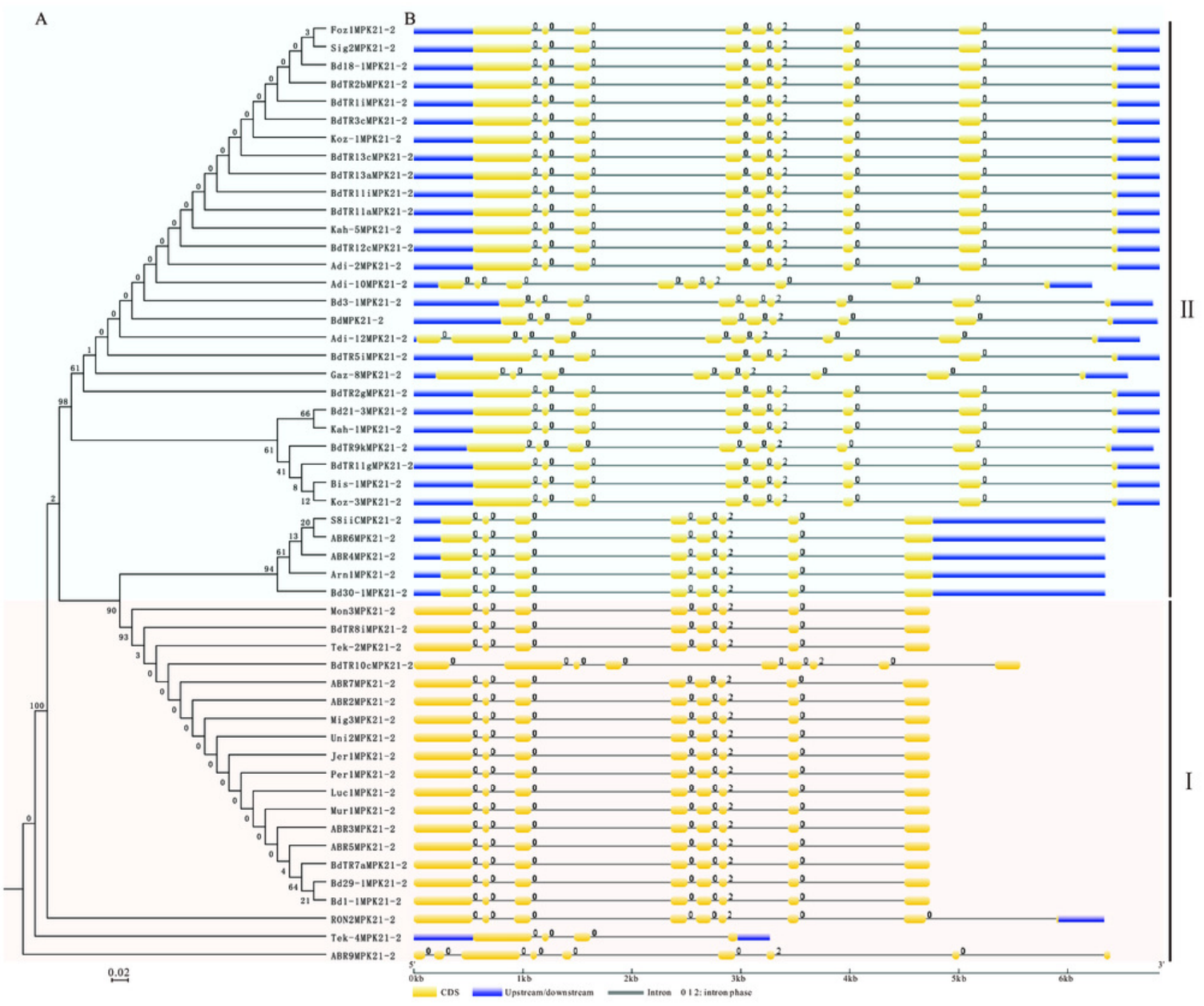




\section{Figure 5}

Conservation and consensus pattern of the EF-hand motif of $B$. distachyon inbred lines MPK17s.

(A) Maximum Likelihood phylogenetic trees of the full sequences of genes encoding MPK17s from $B$. distachyon inbred lines. (B) ClustalW multiple-sequence alignment of the region containing the EF-hand motif within MPK17s. Conserved residues are shown in dark colors.

(C) Consensus pattern and sequence logo of the EF-hand motif generated using the Weblogo3 application ( http://weblogo.threeplusone.com/ ). The overall height of each stack indicates the sequence conservation at that position (measured in bits), whereas the height of symbols within the stack reflects the relative frequency of the corresponding base at that position. (D) ClustalW multiple-sequence alignment of the region containing the EF-hand motif within MPK17 in different plant species. The specific domain was marked by thick line. At: Arabidopsis thaliana; Bd: Brachypodium distachyon; Cru: Capsella rubella; Cc: Citrus clememtina; Cs: Cucumis sativus; Eg: Erythranthe guttata; Egr: Eucalyptus grandis; Gr: Gossypium raimondii; Me: Manihot esculenta; Os: Oryza sativa; Pt: Populus trichocarpa; Sb: Sorghum bicolor; Si: Setaria italica; Tc: Theobroma cacao; Zm: Zea mays. 


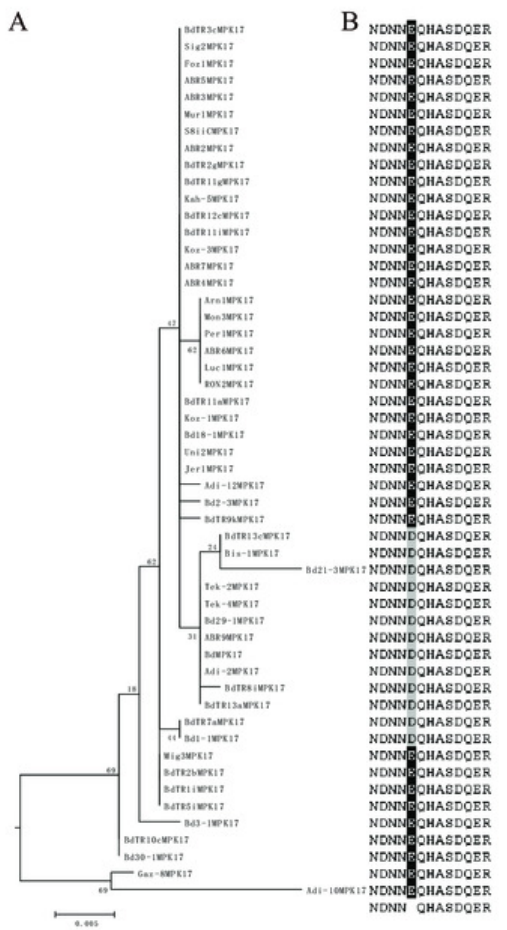

$\mathrm{C}$

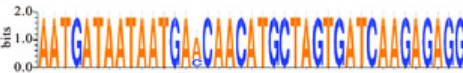

D NDNNEQHASDQER

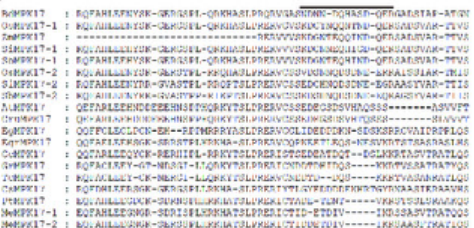




\section{Figure 6}

The diversity and evolution of the fate of an ancestral locus having $B$. distachyon inbred lines MKK10 genes in tandem position.

A. Phylogenetic relationships among 53 diverse $B$. distachyoninbred lines were investigated. The phylogenetic tree is modified from BrachyPan (https://brachypan.jgi.doe.gov/). The variants of ancestral tandem MKK10 gene clusters in B. distachyoninbred lines are shown on the right. The red asterisk indicates the gene cluster models of these inbred lines are same as Bd21, while blue pound represents no tandem duplication events. Gene or protein names: MKK (MAPK kinase 10); DMRL ( DMRL synthase ); Peptidase (Peptidase_C48); PNN (pinin); ChaC (ChaC-like protein); G-patch (glycine rich nucleic binding domain); ATP-synt (ATP synthase subunit C); RRM (RNA recognition motif protein); UDPGT (UDP-glucoronosyl and UDP-glucosyl transferase); ABC (ABC transporter); PK (Protein tyrosine kinase); AP2 (AP2/EREBP transcription factor); DNA_pol_B (DNA polymerase family B); GCH (Predicted glycine cleavage system H protein); MTL23 (Methyltransferase-like protein 23); Ulp1 (Ulp1 protease); SWIM (SWIM zinc finger); Str (Strictosidine synthase). 


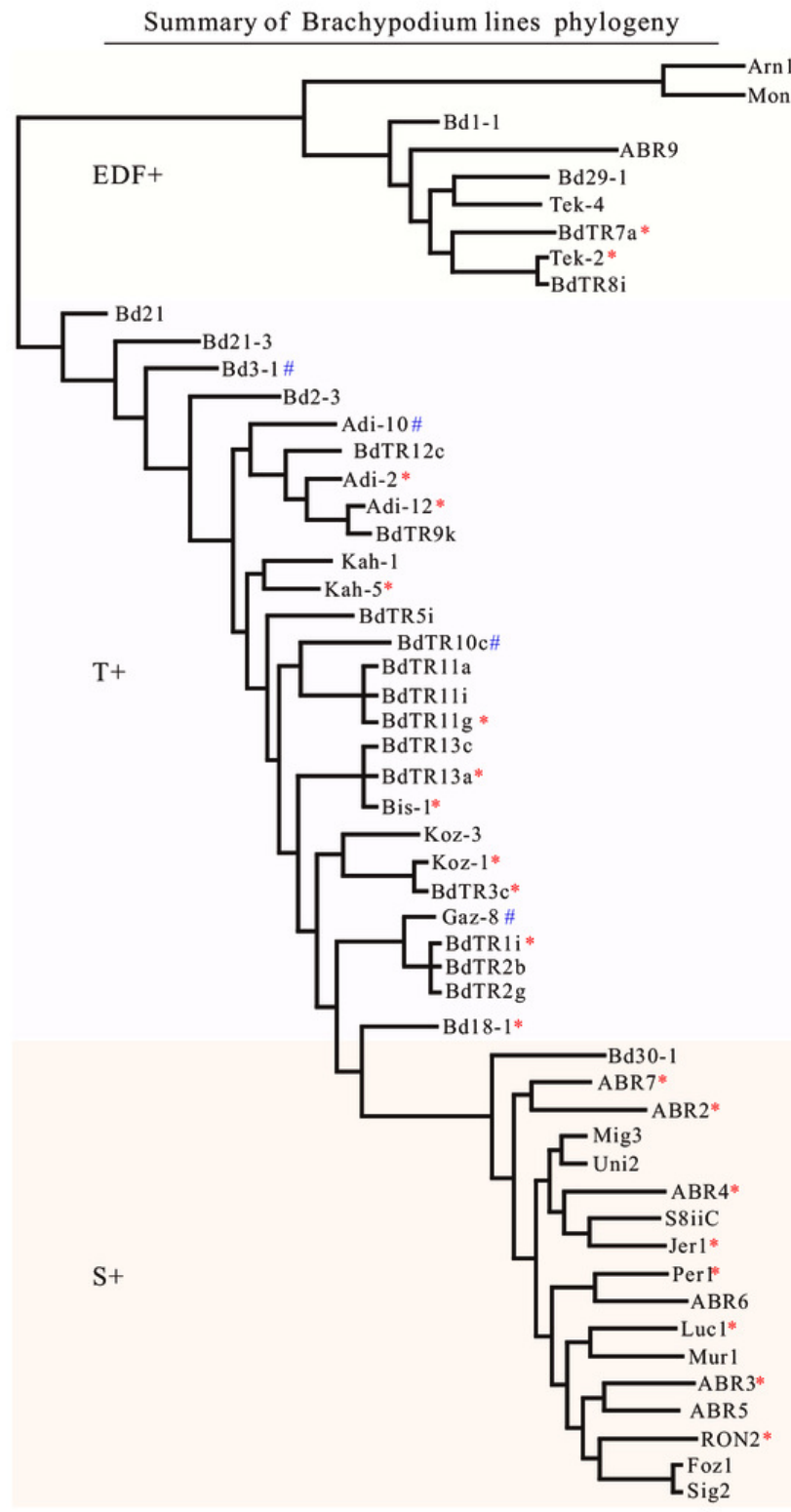

tandem MKK10 gene cluster

MKKDMRDMKK

MKK]DMRD Peptidase(MKK)MKK

MKKDMRDMKK

MKK]MKK $>$ MKN

MKKDMRDMKK

MKKDMRDMKK)MKK

MKKDMRLMKK

MKKDMRDMKK) PKMKK4MKK5 $\bigcirc$ MKK

MKKDMRDMKKChaCMKK

MKKIDMRDG-patchMKK)MKK

MKKDMRDMKKDEABC ATP-sVnTMK

MKKIRRMIMKKDMRDMKK

MKKDMRDMKKOUDPGD UDPGD $\quad$ PNN $\triangle$ MKK MKKDMRDMKK

MKKDMRLABCPR RRMABCMKKIMKK

MKKDMRLMKK

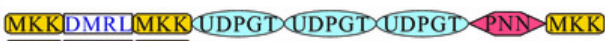
MKKDMRDMKK

MKKDMRLMKK

MKK DMRDMKK AP2 $\triangle D N A$ DOI_BMKK MKK)DMRL(MKK) GCHD CUDPGD MTL23MKK

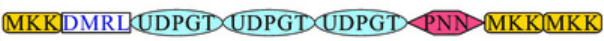

MKK $\bigcirc U D$ SWIMRRMIMKKDMRDPK(MKK

MKKDMRDUDPGDUDPGD MKK

MKKDMRDUDPGD $\bigcirc$ UDPGD $\bigcirc$ UDPGDSEODPGDMKK

MKKDMRDMKK

MKK DMRDPKOPR(MKK 


\section{Figure 7}

Quantitative expression variation of three diverse B. distachyon inbred lines MPK and MKK genes in five different tissues.

Root, stem, leaf blade and leaf sheath samples were collected at the 8-9 leaf stage of BdTR8i, Bd21 and Bd30-1 seedling, respectively. While spikelet samples were harvested at $B$. distachyon flowering one to two weeks according to their different flower time. 


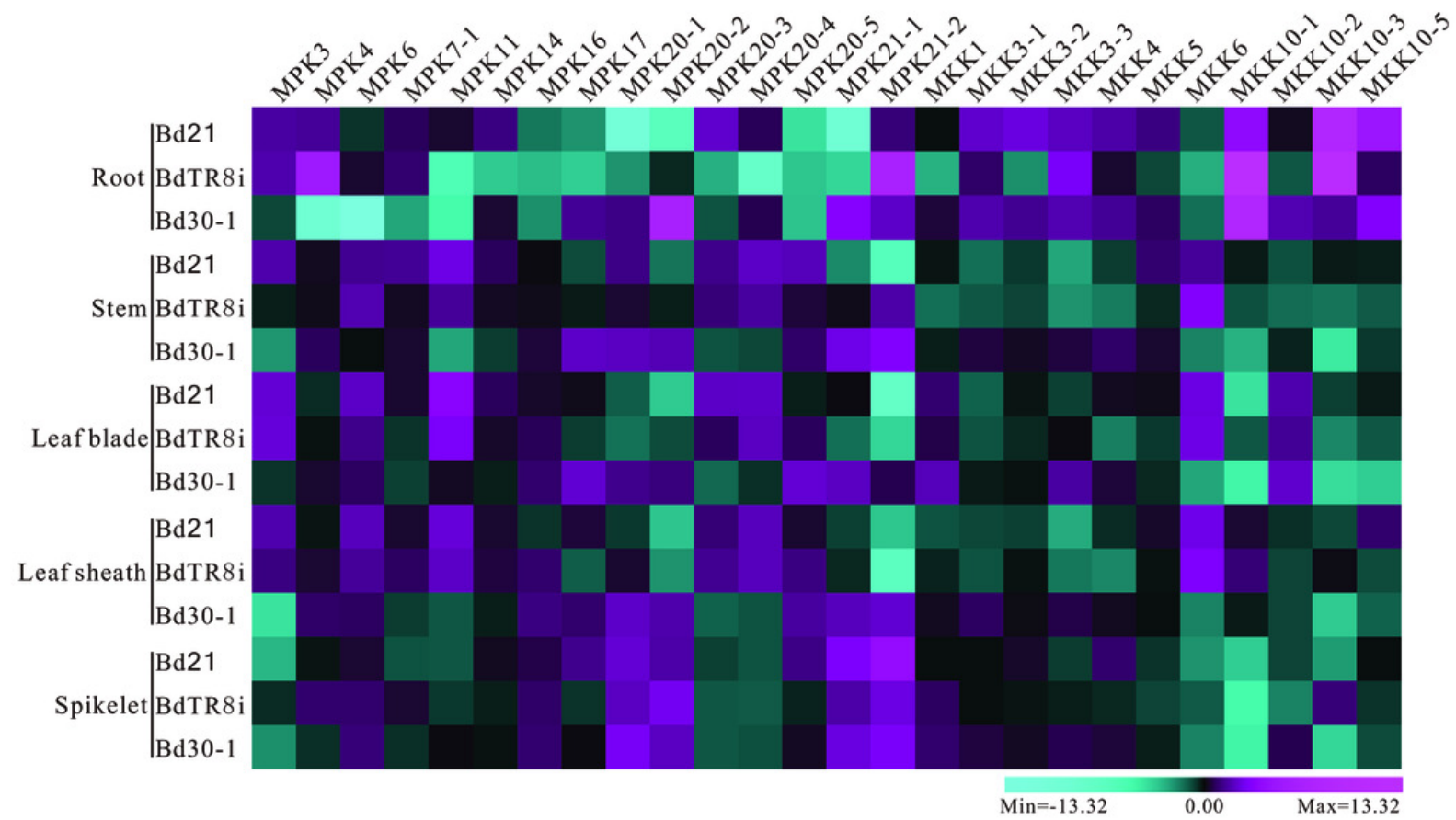


Figure 8

Expression patterns MPK and MKK genes in Bd21, BdTR8i and Bd30-1 seedlings under different abiotic stresses. 


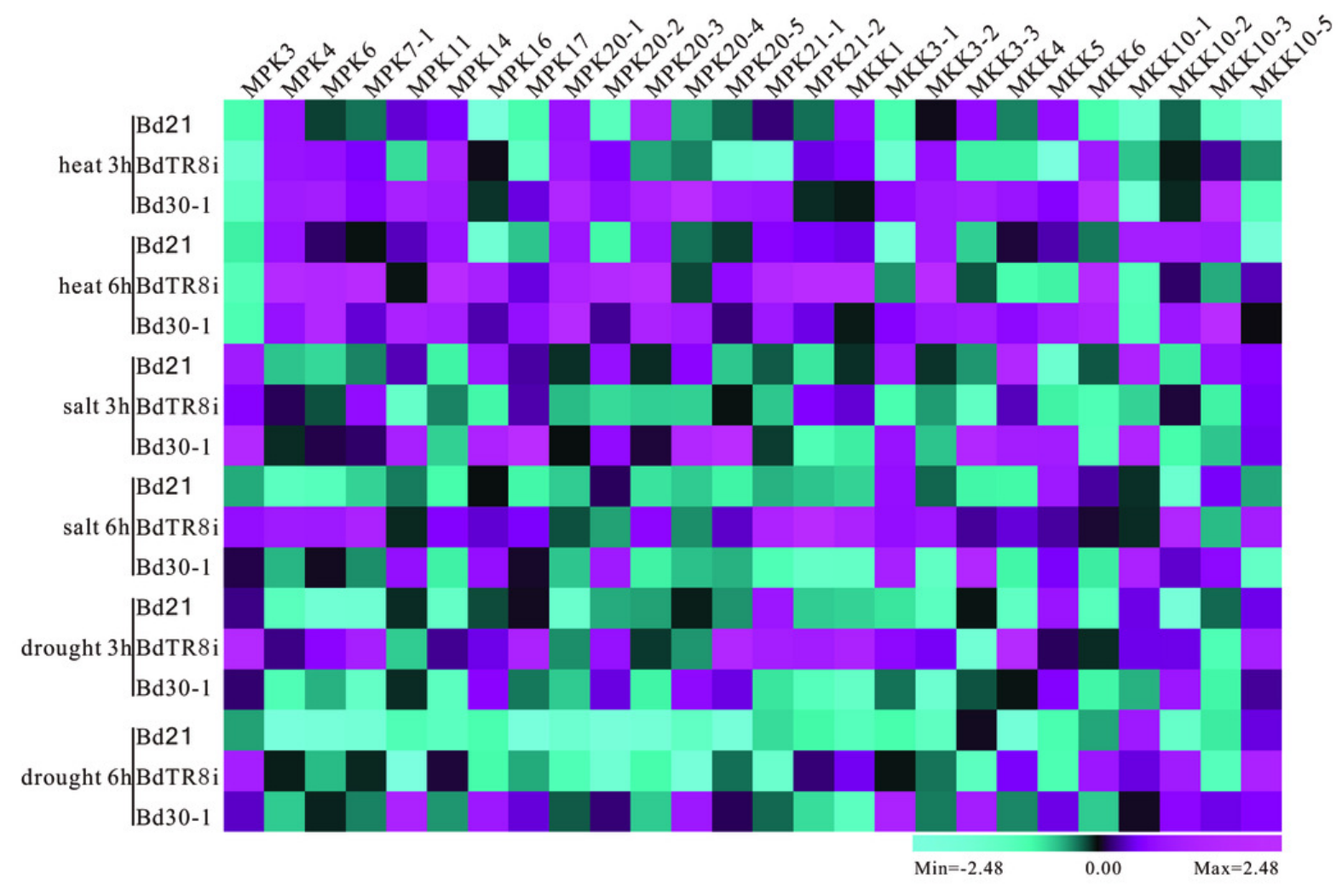




\section{Table $\mathbf{1}$ (on next page)}

Number of $B$. distachyon inbred lines MPKs and MKKs identified genes from the BrachyPan database and their associated information. 
1 Table 1 Number of Brachypodium $M P K$ and $M K K$ genes identified from the BrachyPan

2 database and their associated information.

3

\begin{tabular}{|c|c|c|c|c|c|c|c|}
\hline $\begin{array}{l}\text { Genetic } \\
\text { groups }\end{array}$ & Inbred line & Latitude & Longitude & $\begin{array}{c}\text { Elevation } \\
\text { (m) }\end{array}$ & Ploidy & MPKs & MKKs \\
\hline \multirow{9}{*}{$\mathrm{EDF}+$} & Arn1 & $42^{\circ} 15^{\prime} 23.44^{\prime \prime} \mathrm{N}$ & $0^{\circ} 43^{\prime} 47.46^{\prime \prime} \mathrm{E}$ & 681 & - & 15 & 12 \\
\hline & Mon3 & $41^{\circ} 39^{\prime} 4.75^{\prime \prime} \mathrm{N}$ & $0^{\circ} 12^{\prime} 37.51 " \mathrm{~W}$ & 515 & diploid & 15 & 12 \\
\hline & Bd1-1 & $39^{\circ} 11^{\prime} 27.44^{\prime \prime} \mathrm{N}$ & $27^{\circ} 36^{\prime} 28.59^{\prime \prime} \mathrm{E}$ & 141 & diploid & 14 & 12 \\
\hline & ABR9 & - & - & - & - & 15 & 12 \\
\hline & $\mathrm{Bd} 29-1$ & $44^{\circ} 30^{\prime} 55^{\prime \prime} \mathrm{N}$ & $33^{\circ} 33^{\prime} 23^{\prime \prime} \mathrm{E}$ & 260 & diploid & 15 & 12 \\
\hline & Tek-4 & $41^{\circ} 0^{\prime} 40.1 " \mathrm{~N}$ & $27^{\circ} 31^{\prime} 8.8^{\prime \prime} \mathrm{E}$ & 20 & diploid & 14 & 11 \\
\hline & BdTR7a & $39^{\circ} 44^{\prime} 53.45^{\prime \prime} \mathrm{N}$ & $34^{\circ} 39^{\prime} 1.15^{\prime \prime} \mathrm{E}$ & 1035 & diploid & 15 & 12 \\
\hline & Tek-2 & $41^{\circ} 0^{\prime} 40.1 " \mathrm{~N}$ & $27^{\circ} 31^{\prime} 8.8^{\prime \prime} \mathrm{E}$ & 20 & diploid & 15 & 12 \\
\hline & BdTR8i & $37^{\circ} 6^{\prime} 31.87^{\prime \prime} \mathrm{N}$ & $34^{\circ} 4^{\prime} 17.06^{\prime \prime} \mathrm{E}$ & 2385 & diploid & 15 & 12 \\
\hline \multirow{9}{*}{$\mathrm{T}+$} & $\mathrm{Bd} 21$ & $33^{\circ} 45^{\prime} 39.18^{\prime \prime} \mathrm{N}$ & $44^{\circ} 24^{\prime} 11.07^{\prime \prime} \mathrm{E}$ & 42 & diploid & 16 & 12 \\
\hline & $\mathrm{Bd} 21-3$ & $33^{\circ} 45^{\prime} 39.19^{\prime \prime} \mathrm{N}$ & $44^{\circ} 24^{\prime} 11.08^{\prime \prime} \mathrm{E}$ & 43 & diploid & 14 & 12 \\
\hline & $\mathrm{Bd} 3-1$ & $33^{\circ} 45^{\prime} 39.19^{\prime \prime} \mathrm{N}$ & $44^{\circ} 24^{\prime} 11.08^{\prime \prime} \mathrm{E}$ & 43 & diploid & 14 & 7 \\
\hline & $\mathrm{Bd} 2-3$ & $33^{\circ} 45^{\prime} 39.18^{\prime \prime} \mathrm{N}$ & $44^{\circ} 24^{\prime} 11.07^{\prime \prime} \mathrm{E}$ & 42 & diploid & 14 & 12 \\
\hline & Adi-10 & $37^{\circ} 46^{\prime} 14.5^{\prime \prime} \mathrm{N}$ & $38^{\circ} 21^{\prime} 8.2^{\prime \prime} \mathrm{E}$ & 510 & diploid & 15 & 10 \\
\hline & BdTR12c & $39^{\circ} 44^{\prime} 53.45^{\prime \prime} \mathrm{N}$ & $34^{\circ} 39^{\prime} 1.15^{\prime \prime} \mathrm{E}$ & 1035 & diploid & 15 & 12 \\
\hline & Adi-2 & $37^{\circ} 46^{\prime} 14.5^{\prime \prime} \mathrm{N}$ & $38^{\circ} 21^{\prime} 8.2^{\prime \prime} \mathrm{E}$ & 510 & diploid & 15 & 12 \\
\hline & Adi-12 & $37^{\circ} 46^{\prime} 14.5^{\prime \prime} \mathrm{N}$ & $38^{\circ} 21^{\prime} 8.2^{\prime \prime} \mathrm{E}$ & 510 & diploid & 15 & 12 \\
\hline & BdTR9k & $39^{\circ} 45^{\prime} 10.62^{\prime \prime} \mathrm{N}$ & $30^{\circ} 47^{\prime} 19.07^{\prime \prime} \mathrm{E}$ & 932 & diploid & 15 & 12 \\
\hline
\end{tabular}




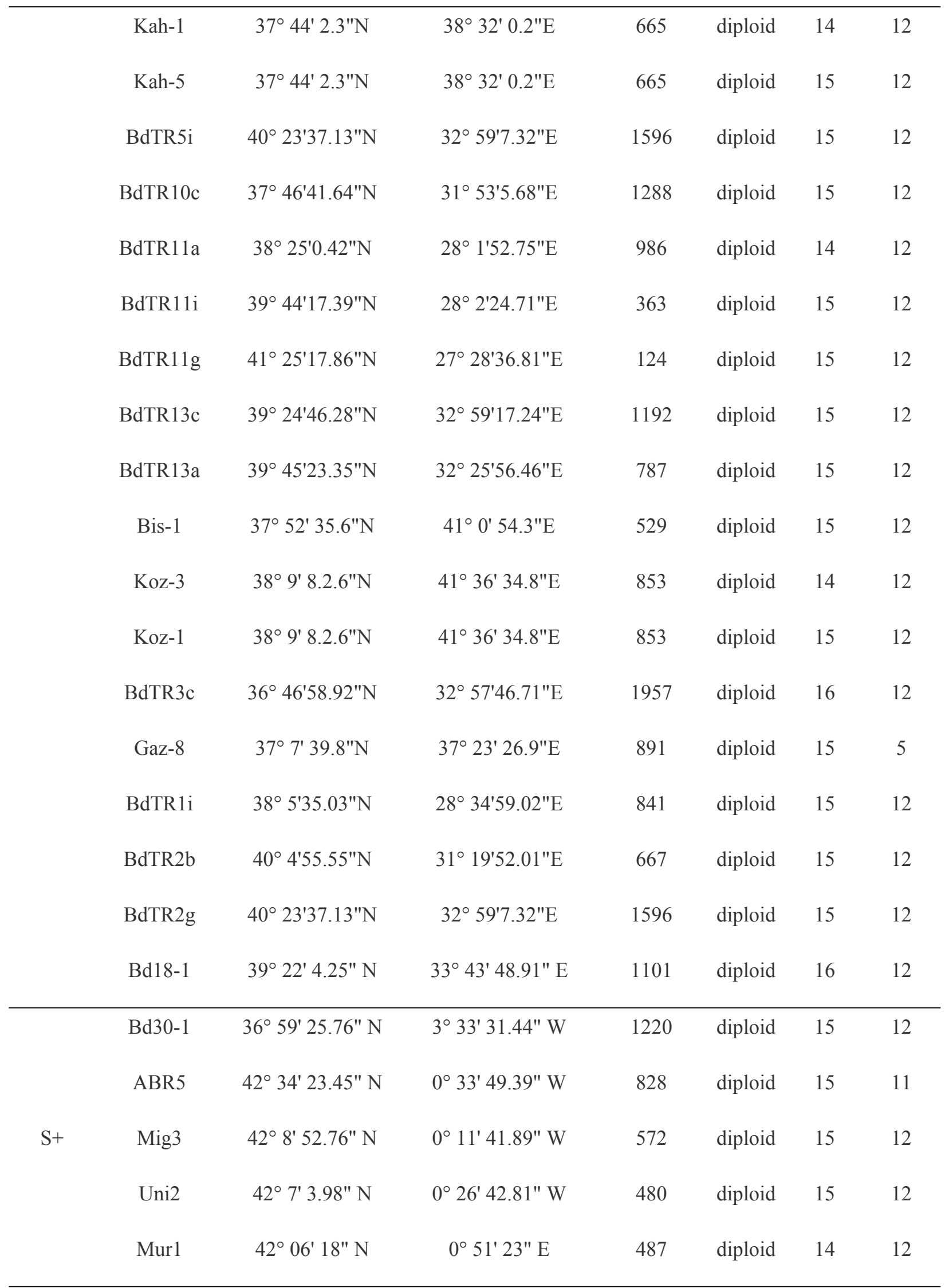




\begin{tabular}{ccccccc}
\hline Foz1 & $42^{\circ} 38^{\prime} 11.44^{\prime \prime} \mathrm{N}$ & $1^{\circ} 18^{\prime} 17.42^{\prime \prime} \mathrm{W}$ & 434 & diploid & 15 & 11 \\
ABR2 & $43^{\circ} 36^{\prime} 15.343^{\prime \prime} \mathrm{N}$ & $3^{\circ} 15^{\prime} 46.580^{\prime \prime} \mathrm{E}$ & 371 & diploid & 14 & 12 \\
ABR3 & $42^{\circ} 10^{\prime} 49.8^{\prime \prime} \mathrm{N}$ & $0^{\circ} 4^{\prime} 23.2^{\prime \prime} \mathrm{W}$ & 1928 & diploid & 14 & 12 \\
ABR4 & $42^{\circ} 15^{\prime} 45.54^{\prime \prime} \mathrm{N}$ & $0^{\circ} 43^{\prime} 0.48^{\prime \prime} \mathrm{E}$ & 480 & - & 15 & 12 \\
ABR6 & $42^{\circ} 34^{\prime} 27.48^{\prime \prime} \mathrm{N}$ & $2^{\circ} 11^{\prime} 5.39^{\prime \prime} \mathrm{W}$ & 484 & - & 15 & 12 \\
ABR7 & $41^{\circ} 35^{\prime} 23.86^{\prime \prime} \mathrm{N}$ & $4^{\circ} 45^{\prime} 24.26^{\prime \prime} \mathrm{W}$ & 725 & - & 14 & 12 \\
S8iiC & $41^{\circ} 36^{\prime} 19.3^{\prime \prime} \mathrm{N}$ & $0^{\circ} 08^{\prime} 38.4^{\prime \prime} \mathrm{E}$ & 144 & - & 15 & 12 \\
Jer1 & $42^{\circ} 3^{\prime} 16.56^{\prime \prime} \mathrm{N}$ & $0^{\circ} 0^{\prime} 44.57^{\prime \prime} \mathrm{W}$ & 418 & - & 14 & 11 \\
Per1 & $42^{\circ} 44^{\prime} 13.34^{\prime \prime} \mathrm{N}$ & $1^{\circ} 44^{\prime} 58.6^{\prime \prime} \mathrm{W}$ & 742 & - & 14 & 12 \\
Luc1 & $42^{\circ} 36^{\prime} 36.18^{\prime \prime} \mathrm{N}$ & $0^{\circ} 53^{\prime} 35.48^{\prime \prime} \mathrm{W}$ & 597 & - & 15 & 12 \\
RON2 & $42^{\circ} 46^{\prime} 50^{\prime \prime} \mathrm{N}$ & $0^{\circ} 57^{\prime} 48^{\prime \prime} \mathrm{W}$ & 594 & - & 15 & 12 \\
Sig2 & $42^{\circ} 36^{\prime} 46.55^{\prime \prime} \mathrm{N}$ & $1^{\circ} 0^{\prime} 52.38^{\prime \prime} \mathrm{W}$ & 524 & - & 14 & 12 \\
\hline
\end{tabular}

4 